\title{
Deep water longline selectivity for black spot seabream (Pagellus bogaraveo) in the Strait of Gibraltar
}

\author{
Ivone Alejandra Czerwinski • \\ Karim Erzini · Juan Carlos Gutiérrez-Estrada · \\ José Antonio Hernando
}

Received: 30 April 2008/Accepted: 17 November 2008/Published online: 4 March 2009

(C) The Japanese Society of Fisheries Science 2009

\begin{abstract}
Species and size selectivity of the deep water longline traditionally used in commercial fishing of the black spot seabream (Pagellus bogaraveo) were studied in the Strait of Gibraltar with four sizes of hooks. Black spot seabream contributed up to $88 \%$ of the catch by number. Catch and by-catch rates differed for the different hooks and fishing trials. Significant differences in average fish length between all hooks, except in one case, were found. The comparison of two experimental fishing trials within 4 years indicates a displacement towards smaller sizes in the size frequency distributions. The results of this study show that the fishing gear can be size selective depending on hook size. The fitted selectivity models for each experiments were very different despite having two hooks in common. This is probably due to the very different catch size distributions in the two periods, which suggests that the population size structure changed significantly between 2000/2001 and 2004/2005.
\end{abstract}

Keywords Hook - Longline - Pagellus bogaraveo . Selectivity

\footnotetext{
I. A. Czerwinski $(\bowtie) \cdot$ J. A. Hernando

Biology Department, Marine and Environmental Faculty, Campus of Puerto Real, Cadiz University, Puerto Real, 11510 Cadiz, Spain

e-mail: ivone.czerwinski@uca.es

K. Erzini

Centre of Marine Sciences (CCMAR), Campus of Gambelas, University of Algarve, 8005-139 Faro, Portugal

J. C. Gutiérrez-Estrada

Agroforestry Sciences Department, Polytechnic University

College, Campus of La Rábida, University of Huelva,

Palos de la Frontera, 21819 Huelva, Spain
}

\section{Introduction}

The black spot seabream (Pagellus bogaraveo) in the Strait of Gibraltar is an economically important fishery species, with an average value of 5.2 million Euros per year (19901994) [1]. Approximately $40 \mathrm{Mt}$ per year were landed in the port of Tarifa between 1972 and 1978, increasing to $100 \mathrm{Mt}$ in 1980. The fishery grew rapidly in the 1980 s, reaching a maximum of $850 \mathrm{Mt}$ of landings in 1984. The decrease in landings since 1995, which was particularly severe in 1998 [2], has lead to management actions by the state and regional administrations to stop this decline and to keep the resource within sustainable limits. In the state administration regulation zone $\left(005^{\circ} 47^{\prime} 95 \mathrm{~W}\right.$ to $\left.005^{\circ} 20^{\prime} 70 \mathrm{~W}\right)$, black spot seabream fishery is carried out exclusively by a vertical deep water longline called "voracera", with a maximum legal length of $120 \mathrm{~m}$. The legal dimensions of the hooks are a minimum length of $3.95 \pm 0.39 \mathrm{~cm}$ and a minimum width of $1.4 \pm 0.14 \mathrm{~cm}$. The minimum landing size in the regulation zone was changed from 25 to $33 \mathrm{~cm}$ in 2003. The allowed fishing season has also been regulated, with a maximum of 140 days per year and a closed season from January 15 to March 31 . There is a total annual quota for the Spanish fleet of $270 \mathrm{Mt}$.

Scientists have studied the relationships between the physical properties of fishing gear and the species and size composition of catches for many years [3]. Estimates of size selectivity of fishing gear provide important information for use in programs focusing on both the conservation and optimum exploitation of fisheries resources [4-6]. While the size-selective nature of gears, such as trawls and gill nets is well known, there is still no clear consensus on the form of the size selection curve for hooks on longlines. Both logistic type models, typically used to describe the selectivity of trawls, and the unimodal models used in 
gillnet selectivity studies have been used in hook selectivity studies [3, 7-19].

Semi-pelagic longline selectivity for the black spot seabream has been already studied in the Azores [18] as well as for other Pagellus species caught with demersal longlines off the south of Portugal [10]. In both cases, the logistic type model seems to be most adequate for describing longline size selectivity for $P$. bogaraveo and Pagellus and other small Sparidae species in general.

In this paper, we present the results of two longline selectivity studies in which four sizes of hooks were used. We fitted the logistic size selectivity model to catch size frequency distributions from the different sizes of hooks. Catch size frequency distributions, estimated catches based on the selectivity models, catch species composition and $P$. bogaraveo average length for the different hooks were compared.

\section{Materials and methods}

Fishing was carried out from a commercial fishing boat (12 $\mathrm{m}$ in length). The "voracera" main line is $80 \mathrm{~m}$ long, consisting of a $1.2-\mathrm{mm}$-diameter monofilament with $1.0-\mathrm{m}$ long and 0.6-mm diameter monofilament gangions spaced $1.10 \mathrm{~m}$ apart. Each main line consists of 70 gangions and is attached to a small sinker and a 3-mm-diameter monofilament line on a hydraulic bobbin. A $20-\mathrm{kg}$ concrete ballast is attached to the end of the longline and is released and left on the bottom when the longline is hauled (Fig. 1). Fishing was carried out on rocky bottoms at depths of up to $850 \mathrm{~m}$. Normal fishing practices in terms of setting, setting time and duration of set were observed. Hooks were baited with standard sized pieces of sardine (Sardina pilchardus) in all longline sets.

Two experimental fishing trials were carried out. In the first experiment (Exp. 1), 50 longline sets were placed between November 2000 and May 2001, with three sizes of round-bent, eyed "Siapal" brand hooks (numbers 9, 10 and 11) and 3500 hooks of each size. In the second experiment (Exp. 2), 106 longline sets were placed between October 2004 and July 2005, with 7420 hooks of each size (numbers 9, 9.5 and 10). The different sized hooks were randomly distributed along the mainline, allowing us to consider the number of contact fish of each size class equal for all hook sizes. Catch rate for each hook size was estimated as number of fish per 100 hooks. Hook dimensions (length, width and depth) are given in Fig. 2.

Using the product of width and length to represent overall hook size [20], we calculated that hook numbers 10 , 9.5 and 9 are 1.12-, 1.26- and 1.40-fold larger than the number 11 hook. Differences between average dimensions of the four hooks were analyzed using a $t$ test. Only the depth dimensions of hooks 10 and 9.5 were not significantly different ( $t=2.359, d f=198, P=0.019$ ).

The choice of a size selectivity model is less obvious for longlines than it is for gillnets and trawl experiments [21], although the logistic selectivity model has been found to be the most appropriate for a variety of Sparidae, including Pagellus acarne and $P$. erythrinus, and a logistic-type selection curve was also obtained for $P$. bogarveo in the Azores using a versatile model that can be used to describe a wide range of selection curves, from bell-shaped to asymptotic [10, 18]. Therefore, it was decided to fit logistic selection curves to the experimental catch data:

$S_{i j}=\frac{1}{1+\mathrm{e}^{-b_{i}\left(l_{j}-L 50_{i}\right)}}$

where $S_{i j}$ is the size selectivity for hook size $i$ and size class $j, b_{i}$ is a parameter determining the slope of the selection curve for hook size $i, l_{j}$ is the mid point of the size class $j$ and $L 50_{i}$ is the length at $50 \%$ selection.

To estimate the parameters of the selection curves, it is assumed that the parameters of the selection curve are a function of hook size $[22,23]$. In our case, mean length, depth, width and overall hook size [20] were used to
Fig. 1 Schematic representation of the "voracera" longline

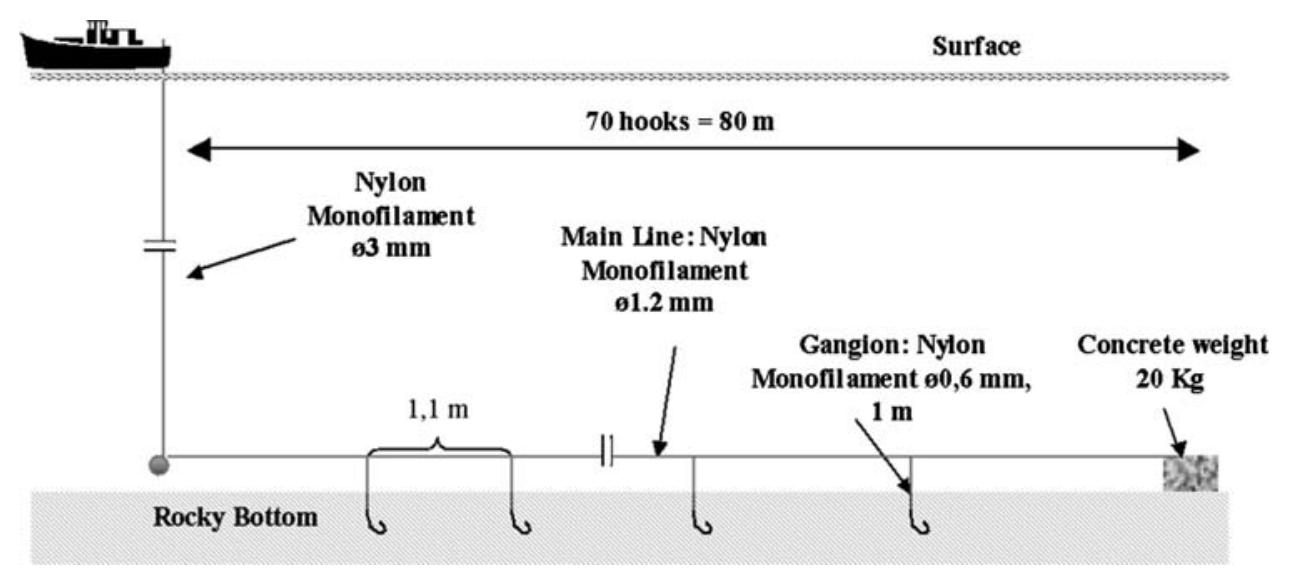


Fig. 2 Shape and dimensions of each type of hook (numbers 9, 9.5, 10 and 11) used in the selectivity study. Means and standard errors (in $\mathrm{cm}$ ) are based on a sample size of 100 hooks for each type

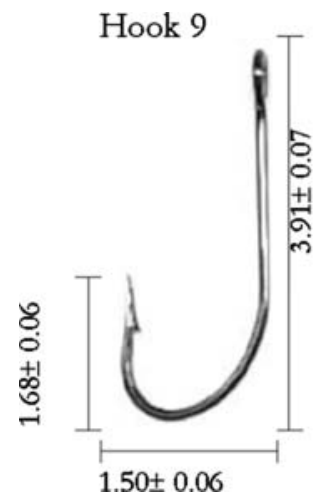

estimate the parameters of the logistic curves as linear functions of hook size:

$b_{i}=A H_{i}+B$

and

$L 50_{i}=C H_{i}+D$

where $A, B, C$ and $D$ are parameters of the linear functions. $H_{i}$ is the mean of each dimension such as width, length and overall hook size for hook size $i$.

The methodology of Wulff [23] and Kirkwood and Walker [22] was used to fit the model. If it can be assumed that the probability of catching a fish of size $j$ with gear size $i$ follows a Poisson distribution, the parameters of the selection curve can be estimated by maximizing the following likelihood function, with the assumption of equal fishing power of the different sized hooks:

$\sum_{i} \sum_{j}\left[C_{i j} \log \left(\frac{S_{i j}}{\sum_{i} S_{i j}}\right)\right]$

where $C_{i j}$ is the observed catches for hook sizes $i$ and size classes $j$. If fishing power is not assumed to be constant, a scaling factor can be included to model optimal selectivity, and the resulting selectivity curves would not be of equal height. A total of 72 models ( 36 for each experiment) were fitted using SAS (ver. 1998; SAS Institute, Cary, NC),

Table 1 Different model types according to the parameters of the logistic curves, estimated as linear functions of hook dimension

\begin{tabular}{lll}
\hline Model type & $b_{i}$ & $L 50_{i}$ \\
\hline 1 & $A H_{i}$ & $C H_{i}$ \\
2 & $A H_{i}$ & $C H_{i}+D$ \\
3 & $A H_{i}+B$ & $C H_{i}$ \\
4 & $A H_{i}+B$ & $C H_{i}+D$ \\
5 & $B$ & $C H_{i}$ \\
6 & $B$ & $C H_{i}+D$ \\
\hline
\end{tabular}

$H_{i}$, Hook size; $b_{i}$, determines the slope of the logistic curve; $L 50$, size at $50 \%$ selection; $A, B, C$ and $D$, constants

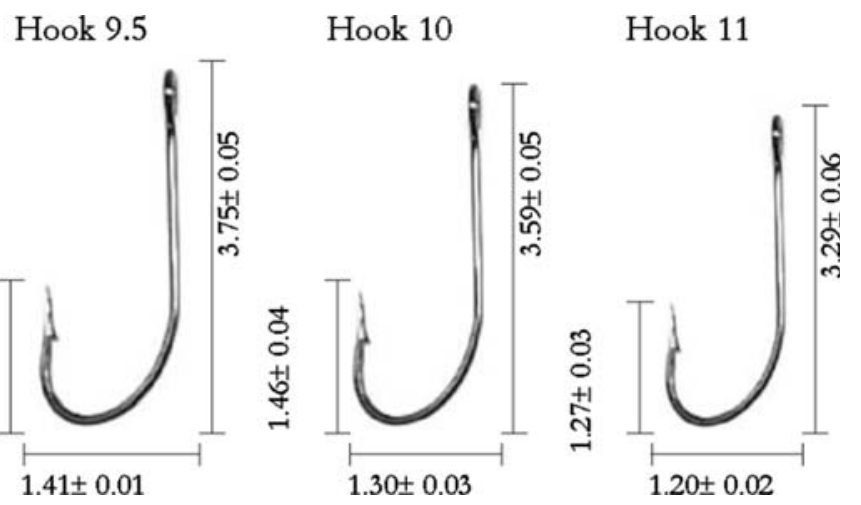

following the six model types of Table 1, for each hook dimension (mean length, depth, width and overall hook size) and for each fish length dimension (total, fork and standard). Expected catches are calculated from the following relationship:

$\hat{C}_{i j}=S_{i j} \hat{N}_{j}$

where

$\hat{N}_{j}=\frac{\sum_{i} C_{i j}}{\sum_{i} S_{i j}}$

where $\hat{C}_{i j}$ is the expected catch and $\hat{N}_{j}$ is the expected number of contact fish.

There are many measures of forecasting accuracy that one may use to compare different models [24]. The correlation between observed and predicted catches was expressed by means of the correlation coefficient $r$. The coefficient of determination $\left(R^{2}\right)$ describes the proportion of the total variance in the observed data that can be explained by the model. Other measures of variances applied were the percentage standard error of prediction (\%SEP) [25], the coefficient of efficiency $\left(E_{2}\right)$ [26] and the average relative variance (ARV) [27]. These four estimators are unbiased estimators that are employed to see how far the model is able to explain the total variance of the data.

The \%SEP is defined by:

$\% \mathrm{SEP}=\frac{100}{\bar{C}} \mathrm{RMSE}$

$\mathrm{RMSE}=\sqrt{\frac{\sum_{i} \sum_{j}\left(C_{i j}-\hat{C}_{i j}\right)^{2}}{n}}$

where $\bar{C}$ is the average of the observed catches, $\hat{C}_{\mathrm{ij}}$ is the estimated catch of the same size class $j$ and hook $i$ and $n$ is the total number of observations. The RMSE is the square root of the mean square error. The principal advantage of $\%$ SEP is its non-dimensionality, which allows comparison on the same basis of forecasts given by different models. 
The coefficient of efficiency $E_{2}$ and the ARV are used to see how the model explains the total variance of the data and represents the "proportion" of the variation of the observed data considered by the model. $E_{2}$ and ARV are given by:

$E_{2}=1.0-\frac{\sum_{i} \sum_{j}\left|C_{i j}-\hat{C}_{i j}\right|^{2}}{\sum_{i} \sum_{j}\left|C_{i j}-\bar{C}\right|^{2}}$

$\mathrm{ARV}=1.0-E_{2}$

The sensitivity to outliers due to the squaring of the difference terms is associated with $E_{2}$ or, equivalently, with ARV. A value of zero for $E_{2}$ indicates that the observed average $\bar{C}$ is as good a predictor as the model, while negative values indicate that the observed average is a better predictor than the model [28].

For a perfect match, the values of $R^{2}$ and of $E_{2}$ should be close to 1 and those of \%SEP and ARV close to 0 .

In addition, it is advisable to quantify the error in the same units of the variables. These measures, or absolute error measures, included the RMSE and the mean absolute error (MAE), given by:

MAE $=\frac{\sum_{i} \sum_{j}\left|C_{i j}-\hat{C}_{i j}\right|}{n}$

\section{Results}

During the Exp. 1 fishing trials, the black spot seabream catch rates for hook numbers 9,10 and 11 were 3.42, 13.04 and $4.48 \%$, respectively. In comparison, during the Exp. 2 fishing trials, the catch rates for hook numbers 9, 9.5 and 10 were $1.93,6.93$ and $7.21 \%$, respectively. Overall, the number 9 hook had the lowest catch rate while the number 10 hook had the highest.

The species caught and fish numbers were different for each experiment (Table 2). In Exp. 1, more than $99 \%$ of the fish caught were $P$. bogaraveo and Helicolenus dactylopterus, with only two fish of two other species. Pagellus bogaraveo contributed up to $89 \%$ of the catch in number in Exp. 1 and up to $92 \%$ in Exp. 2. In Exp. 2, all hooks caught fish of $P$. bogaraveo, $H$. dactylopterus, Trachurus mediterraneus and Scomber japonicus, and hook 10 also caught one individual of Lepidopus caudatus.

There was a strong overlapping of the catch size frequency distributions in both experiments. However, a $t$ test found significant differences in average fish length between all hook sizes in Exp. 1 [ANOVA, $F=15.28, d f=2$, $P<0.01$; least significant differences (LSD) post hoc analysis with $\alpha=0.01$ ) and in Exp. 2 between hooks 9 and 9.5 and between hooks 9 and 10, but there was no significant difference between average fish size for hooks 9.5 and 10 (ANOVA, $F=0.08, d f=2, P<0.01$; LSD post hoc analysis with $\alpha=0.01)$.
To compare fish size frequency distribution of each hook, a Kolmogorov-Smirnov (K-S) test was performed. In Exp. 1, there were significant differences between all hooks (9 and 11: $\mathrm{K}-\mathrm{S}=2.779, P<0.05 ; 10$ and 11: $\mathrm{K}-\mathrm{S}=2.445, P<0.05 ; 9$ and $10: \mathrm{K}-\mathrm{S}=1.476, P>0.05)$. In Exp. 2, the catch size frequency distribution of hook number 10 was not significantly different from that of hook number $9.5(\mathrm{~K}-\mathrm{S}=0.749, \quad P>0.05)$, but there was a significant difference between hook number 9 and the other two hooks (9 and 10: $\mathrm{K}-\mathrm{S}=1.543$, $P<0.05 ; 9$ and 9.5: $\mathrm{K}-\mathrm{S}=1.842 ; P<0.05)$. The catch size frequency distributions by hook size are given in Fig. 3.

In both fishing trials, black spot seabream of a wide size range were caught (Fig. 4). Fish ranging from 23.5 to 52.0 and from 19.5 to $51.5 \mathrm{~cm}$ in fork length were caught in the fishing trials of Exp. 1 and Exp. 2, respectively. While the catch size distributions of Exp. 1 can be seen to be essentially uni-modal but skewed to the right, those of Exp. 2 are clearly multi-modal, with several smaller modes to the right of the main mode corresponding to catches of larger black spot seabream. All comparisons between the distributions of the two experiments showed significant differences $(\mathrm{K}-\mathrm{S}=$ 8.497, $P<0.05)$.

The estimated parameters and accuracy measures for a selection of selectivity models for each experiment are given in Tables 3 and 4. Models that did not give reasonable parameter estimates or failed to converge are not included in the tables.

For Exp.1, only 11 of type 1 and 5 models gave good fits. Simple proportional functions were in all cases adequate for describing the relationships between $L 50$ and hook size $\left(H_{i}\right)$. For Exp. 2, six of type 1, 2 and 5 models gave good fits, with proportional functions describing the relationships between $L 50$ and hook size in most cases. The slope of the selection curves $\left(b_{i}\right)$ was described as a constant or proportional function of hook size in both experiments. While total length was the most adequate fish dimension for describing selection curves as a function of hook dimension in Exp. 1, which in most cases was the overall hook size, in Exp. 2, standard length and in most cases hook depth were the measurements that resulted in the best fits. The $L 50$ values obtained for Exp. 1 varied from 19.29 to $37 \mathrm{~cm}$ and from 34.15 to $49.46 \mathrm{~cm}$ in Exp. 2, while the selection curve slopes $\left(b_{i}\right)$ varied from 0.21 to 3.55 in Exp. 1 and from 0.18 to 0.30 in Exp. 2.

Comparing the forecasting accuracy measures of Exp. 1 models, model No. 10 [type 5 model with constant slope $\left(b_{i}\right)$ and $L 50_{i}$ proportional to overall hook size, based on fork length measurements] showed the highest values of $\% \mathrm{SEP}, E_{2}$ and $R^{2}$, and the lowest value of ARV. In Exp. 2, 
Table 2 Number of fishes caught of each species for the three hooks used in each experiment

Fig. 3 Pagellus bogaraveo catch size frequency distributions for different hook sizes in the two experiments $(E x)$

Fig. 4 Comparison of the $P$. bogaraveo total catch size frequency distributions for the two experiments $(E x)$

\begin{tabular}{|c|c|c|c|c|}
\hline \multirow[t]{2}{*}{ Species } & Hook size numb & & \multirow[t]{2}{*}{ Total catch } & \multirow{2}{*}{$\begin{array}{l}\text { Percentage of } \\
\text { total catch }\end{array}$} \\
\hline & 10 & 11 & & \\
\hline
\end{tabular}

\section{Experiment 1}

Pagellus bogaraveo

Brama brama

Helicolenus dactylopterus

Trachurus mediterraneus

Experiment 2

P. bogaraveo

H. dactylopterus

T. mediterraneus

Scomber japonicus

Lepidopus caudatus

$\begin{array}{rlrrr}120 & 484 & 157 & 761 & 89.8 \\ & 1 & & 1 & 0.1 \\ 5 & 71 & 8 & 84 & 9.9 \\ & 1 & & 1 & 0.1\end{array}$

$\begin{array}{rlrrr}9 & 9.5 & 10 & & \\ 143 & 514 & 535 & 1192 & 92.1 \\ 8 & 18 & 39 & 65 & 5.0 \\ 3 & 20 & 6 & 29 & 2.2 \\ 2 & 3 & 2 & 7 & 0.5 \\ & 1 & & 1 & 0.1\end{array}$

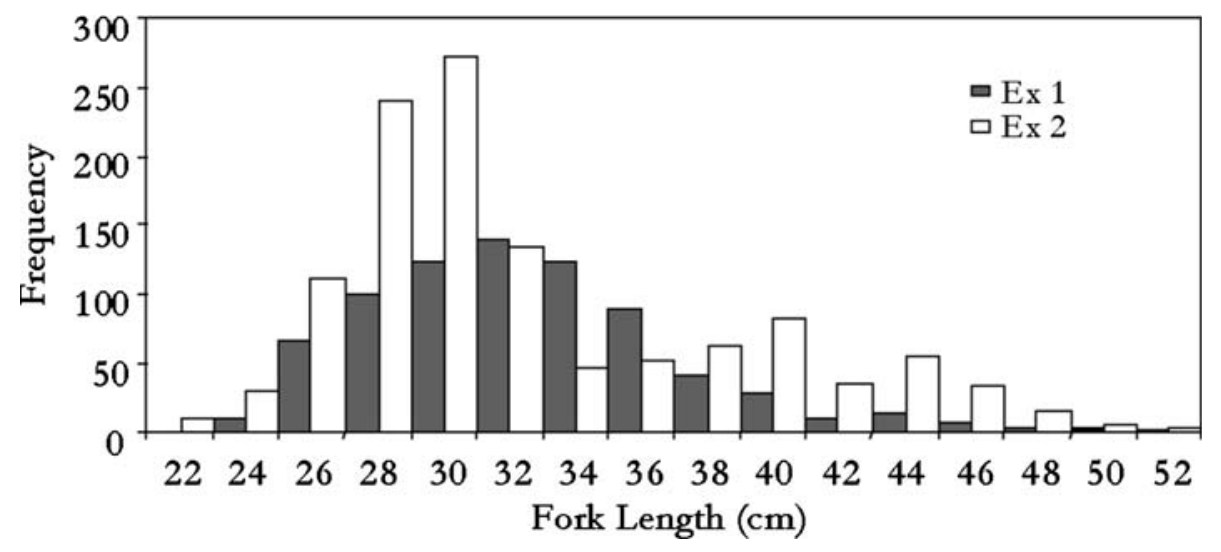


Table 3 Estimated parameters for logistic selectivity curve fitted by maximum likelihood, for each experiment using different fish and hook size dimensions

\begin{tabular}{|c|c|c|c|c|c|c|c|c|c|c|c|c|c|c|}
\hline Experiment & $\begin{array}{l}\text { Model } \\
\text { no. }\end{array}$ & $\begin{array}{l}\text { Model } \\
\text { type }\end{array}$ & $\begin{array}{l}\text { Fish } \\
\text { length }\end{array}$ & $\begin{array}{l}\text { Dimension } \\
\text { of } H_{i}\end{array}$ & $A$ & $B$ & $b_{9}$ & $b_{10}$ & $b_{11}$ & $C$ & $D$ & $L 50_{9}$ & $L 50_{10}$ & $L 50_{11}$ \\
\hline \multirow[t]{12}{*}{1} & 1 & 5 & Total & Overall & & 0.356 & 0.36 & 0.36 & 0.36 & 6.131 & & 35.96 & 28.61 & 24.13 \\
\hline & 2 & 1 & Total & Overall & 0.053 & & 0.31 & 0.25 & 0.21 & 6.309 & & 37.00 & 29.44 & 24.83 \\
\hline & 3 & 5 & Total & Width & & 0.413 & 0.41 & 0.41 & 0.41 & 23.325 & & 34.99 & 30.35 & 27.90 \\
\hline & 4 & 1 & Total & Width & 0.247 & & 0.37 & 0.32 & 0.30 & 23.914 & & 35.87 & 31.11 & 28.60 \\
\hline & 5 & 1 & Total & Depth & 0.284 & & 0.48 & 0.41 & 0.36 & 20.308 & & 34.04 & 29.67 & 25.79 \\
\hline & 6 & 5 & Total & Length & & 0.568 & 0.57 & 0.57 & 0.57 & 8.369 & & 32.72 & 30.02 & 27.53 \\
\hline & 7 & 1 & Total & Length & 0.135 & & 0.53 & 0.48 & 0.44 & 8.496 & & 33.22 & 30.48 & 27.95 \\
\hline & 8 & 5 & Total & Depth & & 1.900 & 1.90 & 1.90 & 1.90 & 17.745 & & 29.74 & 25.93 & 22.54 \\
\hline & 9 & 1 & Standard & Overall & 0.606 & & 3.55 & 2.83 & 2.38 & 4.901 & & 28.74 & 22.87 & 19.29 \\
\hline & 10 & 5 & Fork & Overall & & 0.410 & 0.41 & 0.41 & 0.41 & 5.483 & & 32.16 & 25.59 & 21.58 \\
\hline & 11 & 1 & Fork & Overall & 0.062 & & 0.36 & 0.29 & 0.24 & 5.632 & & 33.03 & 26.28 & 22.16 \\
\hline & & & & & & & $b_{9}$ & $b_{9.5}$ & $b_{10}$ & & & L509 & $L 50_{9.5}$ & $L 50_{10}$ \\
\hline \multirow[t]{6}{*}{2} & 1 & 5 & Total & Depth & & 0.242 & 0.24 & 0.24 & 0.24 & 29.506 & & 49.46 & 43.44 & 43.11 \\
\hline & 2 & 1 & Fork & Depth & 0.120 & & 0.20 & 0.18 & 0.18 & 28.709 & & 48.12 & 42.26 & 41.94 \\
\hline & 3 & 5 & Fork & Depth & & 0.268 & 0.27 & 0.27 & 0.27 & 26.736 & & 44.81 & 39.36 & 39.06 \\
\hline & 4 & 1 & Standard & Depth & 0.130 & & 0.22 & 0.19 & 0.19 & 25.477 & & 42.70 & 37.50 & 37.22 \\
\hline & 5 & 2 & Standard & Depth & 0.153 & & 0.26 & 0.23 & 0.22 & 19.100 & 10.767 & 42.78 & 38.88 & 38.67 \\
\hline & 6 & 5 & Standard & Depth & & 0.301 & 0.30 & 0.30 & 0.30 & 23.374 & & 39.17 & 34.41 & 34.15 \\
\hline
\end{tabular}

$H_{i}$, Dimension of the hook $i(i=9,9.5,10$ and 11$) ; b_{i}$, equation of the slope of the logistic curve; $b_{9-11}$, values of $b_{i}$ for each hook and model no.; $L 50_{i}$, size at $50 \%$ selection for hook $i, L 50_{9-11}$, values of $L 50$ for each hook and model no. $A, B$ and $C, D$ : parameters relating the slope and $L 50$ to hook size, respectively

Table 4 Accuracy measures for logistic selectivity curve fitted, for each experiment

\begin{tabular}{|c|c|c|c|c|c|c|c|}
\hline Experiment & Model no. & RMSE & MAE & $\%$ SEP & $E_{2}$ & ARV & $R^{2}$ \\
\hline \multirow[t]{11}{*}{1} & 1 & 6.975 & 4.662 & 85.349 & 0.573 & 0.427 & 0.574 \\
\hline & 2 & 7.473 & 5.181 & 91.450 & 0.510 & 0.490 & 0.510 \\
\hline & 3 & 7.142 & 4.808 & 87.394 & 0.553 & 0.447 & 0.553 \\
\hline & 4 & 7.224 & 4.882 & 88.404 & 0.542 & 0.458 & 0.542 \\
\hline & 5 & 7.337 & 4.984 & 89.780 & 0.528 & 0.472 & 0.528 \\
\hline & 6 & 7.382 & 5.049 & 90.333 & 0.522 & 0.478 & 0.522 \\
\hline & 7 & 7.560 & 5.226 & 92.512 & 0.499 & 0.501 & 0.499 \\
\hline & 8 & 7.582 & 5.089 & 92.784 & 0.496 & 0.504 & 0.496 \\
\hline & 9 & 8.070 & 4.921 & 95.563 & 0.603 & 0.397 & 0.602 \\
\hline & 10 & 7.303 & 4.842 & 83.598 & 0.615 & 0.385 & 0.608 \\
\hline & 11 & 7.372 & 4.833 & 84.389 & 0.608 & 0.392 & 0.601 \\
\hline \multirow[t]{6}{*}{2} & 1 & 2.211 & 1.587 & 21.698 & 0.976 & 0.024 & 0.975 \\
\hline & 2 & 2.339 & 1.759 & 18.837 & 0.978 & 0.022 & 0.979 \\
\hline & 3 & 2.361 & 1.759 & 19.018 & 0.978 & 0.022 & 0.978 \\
\hline & 4 & 2.990 & 1.984 & 21.826 & 0.974 & 0.026 & 0.974 \\
\hline & 5 & 2.992 & 1.983 & 21.840 & 0.974 & 0.026 & 0.974 \\
\hline & 6 & 3.002 & 2.010 & 21.912 & 0.974 & 0.026 & 0.974 \\
\hline
\end{tabular}

RMSE, Square root of the mean square error; MAE, mean absolute error; \%SEP, percentage standard error of prediction; $E_{2}$, the coefficient of efficiency; ARV, average relative variance; $R^{2}$ coefficient of determination

model No. 2 [type 1 model with slope $\left(b_{i}\right)$ and $L 50_{i}$ proportional to depth hook dimension, based on fork length measurements] had the best values for $\% \mathrm{SEP}, E_{2}$, ARV and
$R^{2}$. In both experiments, models with the lowest RMSE and MAE values were not the models with the best \%SEP, $E_{2}$, $\mathrm{ARV}$ and $R^{2}$ values. 
Fig. 5 Logistic selection curves of the longline, obtained from the selectivity model No. 10 of Exp. 1 and No. 2 of Exp. 2
Fig. 6 Comparison of the observed and predicted catch size frequency distributions for the three hook sizes according to the logistic selectivity model of each experiment
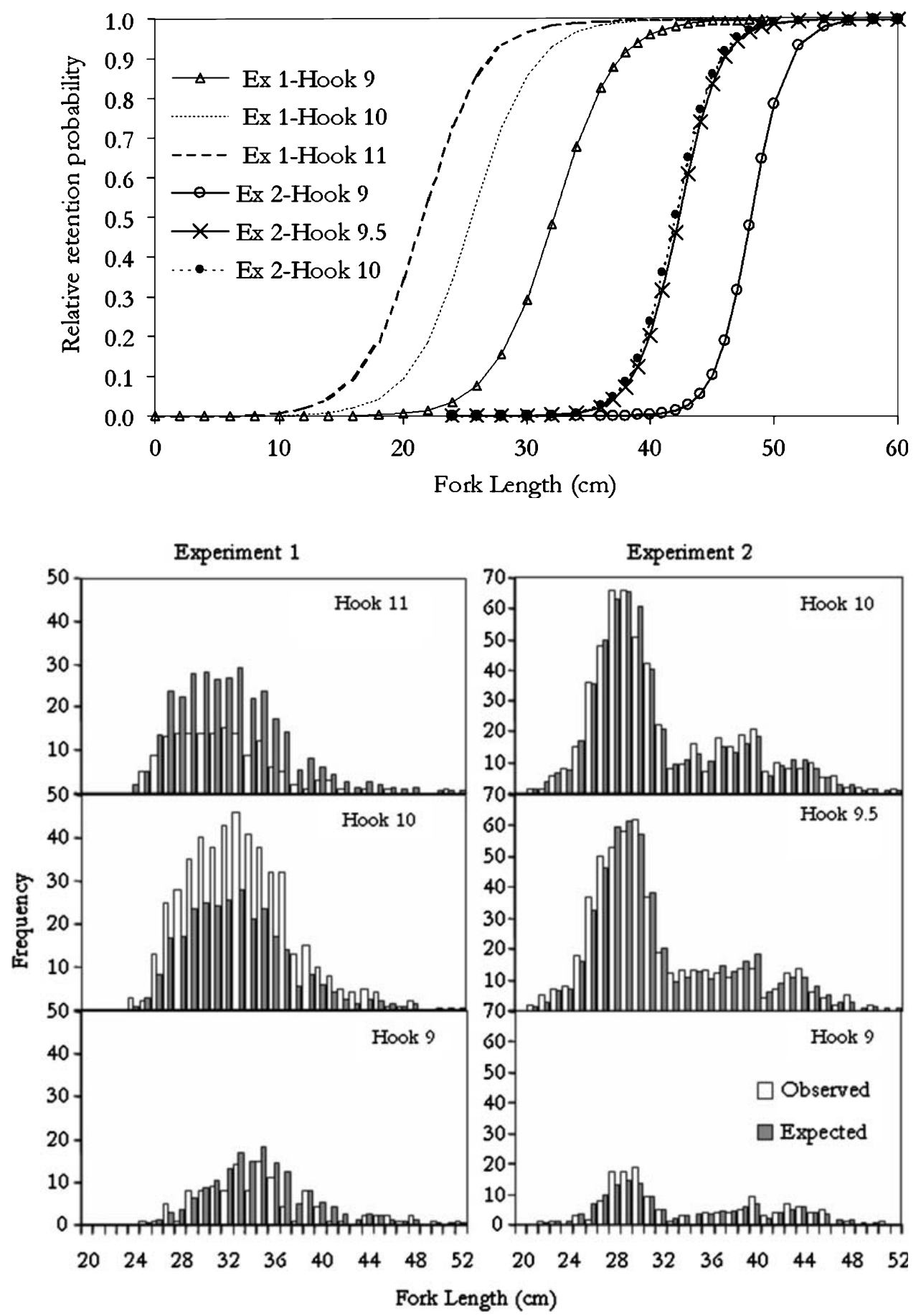

Models No. 10 of Exp. 1 and No. 2 of Exp. 2, were selected as the best based on their values of \%SEP, ARV and $R^{2}$. Differences in the chosen models can be appreciated in the $L 50$ values (in Exp. 1, 32.2-, 25.6- and 22.4-cm fork length for hooks 9, 10 and 11, respectively; in Exp. 2, 48.1-, 42.3- and 41.9-cm fork length for hooks 9, 9.5 and 10 , respectively) as well as the slopes of the curves $(0.41$ for all three hook sizes in Exp. 1; 0.20 for hook 9 and 0.18 for hooks 9.5 and 10 in Exp. 2).
The selection curves for both experiments are shown in Fig. 5. The observed catches and the expected catches based on these models are given in Fig. 6. In Exp. 1, observed frequencies for hook 11 were lower than the expected, while observed frequencies for hook 10 were rather higher than the expected. However, such differences were not observed in Exp. 2. As can be seen, better fits were obtained for Exp. 2 than for Exp. 1. This was confirmed by the results of forecasting accuracy measures. 


\section{Discussion}

The longline used in this study can be considered to be highly species selective given the small proportion of nontarget species caught, confirming that hook and line gear can be highly species selective through a manipulation of hook size and bait type [29]. The number of captured species (nine) is lower than that reported in other similar longline fisheries, such as the black spot seabream fishery in the Azores, where 27 species were caught, with the most important species being $H$. dactylopterus followed by $P$. bogaraveo. This difference could be due to geographic differences, gear characteristics and fishing strategy differences, since the fishing experiments in the Azores were carried out with semi-pelagic longlines and the hooks were of different sizes from the ones used in the Strait of Gibraltar (hooks numbers 12, 9, 6 and 4 in the Azores study). In Algarve (south Portugal), 35 species of fish and cephalopods were reported in a similar study in which three smaller hooks (numbers 15, 13 and 11) were used in much shallower depths (between 13 and $20 \mathrm{~m}$ ) [9].

Our comparison of the catch size frequency, distributed over both experiments, revealed a displacement of the distribution towards smaller sizes over time. Similar changes have been observed in the size composition of exploited populations of Squalus acanthias [30], sharks, rays and chimaerae [31], Ammodytes marinus [32], Sander lucioperca [33] and different species from the communities of coral reefs [34]. Variations in fish population size frequency distributions have been identified as possible indicators of the impact of fishing [35]. In the case of the black spot seabream, the results of our comparison of the two experimental fishing trials indicate a displacement towards smaller sizes in the size frequency distributions. Very similar size frequency distributions were observed from 1990 to 1994 [36]. Nevertheless, the catch size composition began to change after 1995, with diminishing catches of larger individuals and significant increases in smaller sized black spot seabream.

The efficiency and the size selectivity of hook gears are influenced by numerous factors, such as the distribution of the fish, competition between fish, size and design of hook, size and forms of bait, combination of baits, duration of sets and the time of the day of fishing [19, 37-41]. Previous studies of selectivity of hooks have used a wide range of sizes and types of hooks and have reached different conclusions.

Otway and Craig [20] evaluated the size selectivity of Pagrus auratus using hooks of three sizes. With differences in the absolute hook size of only 26.5 and $65 \%$, they found that the smaller hook caught more illegal size fishes ( $<20 \mathrm{~cm}$ in fork length), whereas the larger hook caught relatively bigger fishes. In some studies, hook size selectivity was only demonstrated using hooks that were different by more than $200 \%$ in absolute size, and even then only small differences in the catch size structures of small species were found [11-13, 19]. These studies showed that the efficiency decreased with increasing size of the hook and that all hook sizes captured the same size range of fish. In other cases, the conclusion drawn by researchers was that there was no difference in the size selectivity with maximum differences in the absolute hook size of 72 and $96 \%[17,42]$. The results of this study show that the "voracera" fishing gear can be selective in terms of sizes based on the size of hook used. The catch size frequency distributions of different sizes of hooks used in this study also show a high degree of overlap, but even though differences in hook size did not surpass $43.7 \%$, there was evidence of size selectivity. It has been reported that bait size can be more important that hook size in determining the size of captured fish [40]. However, in this study standardized pieces of sardine were used as bait.

Although there is no consensus on the form of the hook selection curve, the logistic model of selectivity was chosen as the most adequate for the black spot seabream longline fishery, as in other largely seabream-based longline fisheries [10, 18, 43]. A decrease in the selectivity for larger sizes may be expected [17], but it was also found that the population size structure can limit the possibilities of a total recognition of selectivity effects. A considerable ambiguity in the form of the selection curve (normal type or sigmoidal curves) indicates that fish catch size frequency distributions may not be sufficiently informative to allow a meticulous evaluation of the real shape of the hook selection curve [14]. Nevertheless, the black spot seabream caught in this study had a wide size range, with the largest fish $(57.8 \mathrm{~cm}$ in total length) approaching the population $L \infty$ of $58 \mathrm{~cm} \mathrm{[36].}$

Total catches of the two experiments showed differences in the size frequency distributions, implying that the population size structures for the two periods differed. In the same way, the fitted selectivity models for each experiment were very different despite having two hooks in common. The differences in the selectivity curves for the two periods (2000/2001 and 2004/2005) probably reflects the different population size structures. A simulation study revealed that size selectivity and fishing mortality strongly influenced the mean size dynamics of the black spot seabream and that logistic type selectivity had a greater effect on the population mean size than normal type selectivity [43]. This result suggests that in this fishery, there is an interrelationship between population size structure and the longline size selectivity.

A multicriteria performance assessment based on different accuracy measures was appropriate for selecting the best models [28]. In some cases, the explained variances 
were significantly high, indicating good model performance, but the values of RMSE, \%SEP, $E_{2}$, ARV and MAE were significantly worse than those obtained with others models. In this way, high correlations can be achieved by mediocre or poor models. Similar conclusions were obtained in the forecasting of different kinds of time variables [44-48].

The obtained accuracy measures were different for the two experiments. In Exp. 1, estimated catches were more different from the observed ones than in Exp. 2. The main reason for these differences and the lack of accuracy in Exp. 1 is that, in all cases, the estimated catch rate decreases with increasing hook size, but in Exp. 1 the intermediate sized hook shows the highest observed catch rate. It can be assumed that all hook size selection curves have the same maximum height if the fishing power of the different hook sizes is equivalent [14]. If the discordance of the model in Exp. 1 is due to the assumption of equal fishing power for all size hooks, this is not the case in Exp. 2. The fishing intensity of hooks can be affected by a variety of factors, such as hook size, hook model, bait type or bait size. In this experiment only hook size was varied. While it is to be expected that larger hooks have lower catch rates [41], in Exp. 1 the catch rate of the smallest hook (hook 11) was significantly lower. This decrease in the catch rate of the smallest hook undermines the assumption of fishing intensity as a function of hook size. In the Azorean fishery of $H$. dactilopterus and P. bogara$v e o$, a similar pattern with the smallest of four hook sizes was observed, suggesting that loss of efficiency could be due to bait loss, since both hook size and sardine bait texture could contribute to bait loss for the smallest hooks [18]. The main reason for the lack of accuracy in Exp. 2 could be due to the overlapping of the catch size frequency distributions of different hook sizes. A possible deduction that could be drawn from these differences in both experiments is that the assumption of equal fishing power for all size hooks could be more correct when the difference between hook sizes is small, as is the case for Exp. 2, or if the size range of the hooks does not include small hooks from which the bait is lost.

In Exp. 2, there were no significant differences between the size frequency distributions of hooks 9.5 and 10 catches, which did not differ significantly in terms of average depth dimension. In all of the fitted models, size selectivity was a function of hook depth dimension, a parameter that differed little between hooks 9.5 and 10 . This could be a key hook size parameter for management purposes in this fishery.

The importance of hook selectivity in a black spot seabream fishery was noted in a previous study, and the effects of hook size selectivity on the size structure were reported for a simulated black spot seabream population.
As this is a protandric hermaphrodite species, where the biggest individuals are females, a decrease in the average size would contribute to the decline of spawning biomass, thereby increasing the probability of recruitment failure [43]. This could indicate that one of the reasons for the observed decline in recruitment in the Strait of Gibraltar is the over-fishing of first mature females $(4+$ age class females with an average total length of $33.1 \pm 2.23 \mathrm{~cm}$ [36]). In the Strait of Gibraltar, the sexual inversion of the black spot seabream takes place at an estimated size of $32.5 \mathrm{~cm}$ total length [36], and the minimum legal size is currently $33 \mathrm{~cm}$ total length. Based on the fitted selectivity models, only hook 9 in Exp. 1 and all hooks in Exp. 2 have a $L 50$ greater than the size of sexual inversion. Nevertheless, smaller individuals exceed $50 \%$ of landings, even in Exp. 2. This suggests that although hooks are selective, the sizes used in this study catch a high number of illegal sized fishes, given the current population size structure. Even if the selectivity model fitted in Exp. 2 shows low selectivity for illegal sizes, the higher relative number of smaller fish sizes produce high catches of these sizes.

Acknowledgments This work has been partly financed by the Agro alimentary and Fishery Research and Formation Institute (IFAPA) (project: C03-007-2003-110), the General Direction of Fishery and Aquaculture of the Council of Andalucía and the Provincial Deputation of Cadiz. The University of Cadiz provided the necessary facilities for a stay at the Universidade do Algarve. We would like to express our gratitude to our colleagues Dr. Mila C. Soriguer, Dr. Cristina Zabala, Dr. Eva Velasco, $\mathbf{M}^{\mathrm{a}}$ Carmen Gómez Cama, Remedios Cabrera, Javier Llorente and Jose M. García Rebollo for the assistance they willingly provided during the samplings. We also thank two anonymous reviewers for their helpful comments and suggestions for improving the manuscript.

\section{References}

1. Jiménez-Toribio R, García-del-Hoyo JJ (2006) Evidence of market price leadership in the Spanish red seabream value chain: implications for fisheries management. Fish Res 81:51-59

2. Manzano Harriero C, Martín Martín J, Merino Martinez E (2001) Actuaciones en investigacion pesquera y acuícola 1997-2000. Consejería de Agriculura y Pesca, Junta de Andalucía, Sevilla

3. Clark JR (1960) Report on selectivity of fishing gear. In: Fishing effort, the effects of fishing on resources and the selectivity of fishing gear, vol 2. ICNAF Special Publication. ICNAF, Dartmouth, pp 27-36

4. Hilborn R, Walters CJ (1992) Quantitative fisheries stock assessment: choice, dynamics and uncertainty. Chapman \& Hall, London

5. Beverton R, Holt S (1993) On the dynamics of exploited fish populations. Chapman \& Hall, London

6. Quinn TJ, Deriso RB (1999) Quantitative fish dynamics. Oxford University Press, New York

7. Brock VE (1999) On the nature of the selective fishing action of longline gear. Pac Sci 16:3-14

8. Cortez Zaragoza E, Dalzell P, Pauly P (1989) Hook selectivity of yellowfin tuna (Thunnus albacares) caught off Darigayos Cove, La Union, Philippìnes. J Appl Ichthyol 1:12-17 
9. Erzini K, Gonçalves JMS, Bentes L, Lino PG, Cruz J (1996) Species and size selectivity in a Portuguese multispecies artisanal long-line fishery. ICES J Mar Sci 53:811-819

10. Erzini K, Gonçalves JMS, Bentes L, Lino PG, Ribeiro J (1998) Species and size selectivity in a 'red' seabream longline 'metier' in the Algarve (southern Portugal). Aquat Living Resour 11:1-11

11. Kanda K, Koike A, Takeuchi S, Ogura M (1978) Selectivity of the hook for mackerel, Scomber japonicus houttuyn, pole fishing. J Tokyo Univ Fish 64:109-114

12. Koike A, Takeuchi S, Ogura M, Kanda K, Arihara C (1968) Selection curve of the hook of long-line. J Tokyo Univ Fish 55:77-82

13. Koike A, Kanda K (1978) Selectivity of the hook of pod smelt, Hypomesus olidus. J Tokyo Univ Fish 64:115-123

14. Millar RB, Holst R (1997) Estimation of gillnet and hook selectivity using log-linear models. ICES J Mar Sci 54:471-477

15. Pope JA, Margetts AR, Hamley JM, Akyuz EF (1975) Manual of methods for fish stock assessment. Part III. Selectivity of fishing gear. FAO Fisheries Technical Paper No 41. FAO, Rome

16. Ralston $S$ (1982) Influence of hook size in the Hawaiian deep-sea handline fishery. Can J Fish Aquat Sci 39:1297-1302

17. Ralston S (1990) Size selection of snappers (Lutjanidae) by hook and line gear. Can J Fish Aquat Sci 47:696-700

18. Sousa F, Isidro E, Erzini K (1999) Semi-pelagic longline selectivity for two demersal species from the Azores: the black spot seabream (Pagellus bogaraveo) and the bluemouth rockfish (Helicolenus dactylopterus dactylopterus). Fish Res 41:25-35

19. Takeuchi S, Koike A (1969) The effect of size and shape of hook and the catching efficiency and selection curve of long-line. $\mathrm{J}$ Tokyo Univ Fish 55:119-124

20. Otway NM, Craig JR (1993) Effects of hook size on the catches of undersized snapper Pagrus auratus. Mar Ecol Prog Ser 93:9-15

21. Woll AK, Boje J, Holst R, Gundersen AC (2001) Catch rates and hook and bait selectivity in longline fishery for Greenland halibut (Reinhardtius hippoglossoides, Walbaum) at East Greenland. Fish Res 51:237-246

22. Kirkwood GP, Walker TI (1986) Gill net mesh selectivities for gummy shark, Mustelus antarcticus, taken in southeastern Australian waters. Aust J Mar Fresh Res 37:689-697

23. Wulff A (1986) Mathematical model for selectivity of gill nets. Arch Fish Wiss 37:101-106

24. Abrahart RJ, See L (2000) Comparing neural network and autoregressive moving average techniques for the provision of continuous river flow forecasts in two contrasting catchments. Hydrol Process 14:2157-2172

25. Ventura S, Silva M, Pérez-Bendito D, Hervás C (1995) Artificial neural networks for estimation of kinetic analytical parameters. Anal Chem 67:1521-1525

26. Kitanidis PK, Bras RL (1980) Real time forecasting with a conceptual hydrological model 2. Applications and results. Water Resour Res 16:1034-1044

27. Griñó R (1992) Neural networks for univariate time series forecasting and their application to water demand prediction. Neural Netw World 2:437-450

28. Legates DR, McCabe GJ Jr (1999) Evaluating the use of 'goodness-of-fit' measures in hydrologic and hydroclimatic model validation. Water Resour Res 35:233-241

29. Bjordal A (1989) Recent advances in longline gear-catching performance selectivity and conservation aspects. In: Proc of the World Symp on Fish Gear and Fish Boat Design. Newfoundland and Labrador Institute of Fisheries and Marine Technology, St. John's, pp 19-24

30. Rago PJ, Sosebee KA, Brodziak JKT, Murawski SA, Anderson ED (1998) Implications of recent increases in catches on the dynamics of Northwest Atlantic spiny dogfish (Squalus acanthias). Fish Res 39:165-181

31. Stevens JD, Bonfil R, Dulvy NK, Walker PA (2000) The effects of fishing on sharks, rays, and chimaeras (chondrichthyans), and the implications for marine ecosystems. ICES J Mar Sci 57:476494

32. Bergstad OA, Hoines AS (2001) Effects of exploitation on age and size structure of sandeel, Ammodytes marinus, populations in the North Sea. Arch Fish Mar Res 49:3-18

33. Balik I, Cubuk H, Ozkok R, Uysal R (2004) Size composition, growth characteristics, stock analysis of the pikeperch, Sander lucioperca (L. 1758), population in Lake Egirdir. Turk J Vet Anim Sci 28:715-722

34. Ault JS, Smith SG, Bohnsack JA (2005) Evaluation of average length as an estimator of exploitation status for the Florida coralreef fish community. ICES J Mar Sci 62:417-423

35. Rochet MJ, Trenkel VM (2003) Which community indicators can measure the impact of fishing? A review and proposals. Can J Fish Aquat Sci 60:86-99

36. Gil J (2006) Biología y pesca del voraz [Pagellus bogaraveo (Brünich, 1768)] en el estrecho de Gibraltar. PhD thesis. Universidad de Cádiz, Cadiz

37. Arimoto T, Ogura M, Inoue Y (1982) Catch variation with immersion time of gear in coastal set-line. Bull Jpn Soc Sci Fish 49:705-709

38. Anonymous (1983) Circle hooks outfish traditional halibut hooks. Mar Fish Rev 45:10-12

39. Skeide R, Bjordal A, Løkkeborg S (1986) Testing of a new hook design (E-Z-Baiter) through comparative longline fishing trials. ICES CM B:25

40. Løkkeborg S, Bjordal A (1992) Species and size selectivity in long-line fishing: a review. Fish Res 13:311-322

41. Bjordal A, Løkkeborg S (1996) Longlining. Blackwell, Oxford

42. Bertrand J (1988) Selectivity of hooks en the handline fishery of the Saya de Malha Banks (Indian Ocean). Fish Res 6:249-255

43. Erzini K, Salgado M, Castro M (2006) Dynamics of black spot seabream (Pagellus bogaraveo) mean length: evaluating the influence of life history parameters, recruitment, size selectivity and exploitation rates. J Appl Ichthyol 22:183-188

44. Garrick M, Cunnane C, Nash JE (1978) A criterion of efficiency for rainfall-runoff models. J Hydrol 36:375-381

45. Willmott CJ, Ackleson SG, Davis RE, Feddema JJ, Klink KM, Legates DR, O'Donnell J, Rowe CM (1985) Statistics for the evaluation and comparison of models. J Geophys Res 90:89959005

46. Stergiou KI, Christou ED, Petrakis G (1997) Modelling and forecasting monthly fisheries catches: comparison of regression, univariate and multivariate time series methods. Fish Res 29:5595

47. Pulido-Calvo I, Portela MM (2007) Application of neural approaches to one step daily flow forecasting in Portuguese watersheds. J Hydrol 332:1-15

48. Velo-Suárez L, Gutiérrez-Estrada JC (2007) Artificial neural network approaches to one-step weekly prediction of Dinophysis acuminata blooms in Huelva (Western Andalucía, Spain). Harmful Algae 6:361-471 